\title{
SEM CONCILIAÇÃO! RANGIDOS DA LUTA INSUBMISSA DO TEATRO DE CAROLINA BIANCHI
}

\section{NO CONCILIATION! GROANING FROM THE UNSUBMITTED STRUGGLE OF THE CAROLINA BIANCHI THEATER}

Rafael Limongelli ${ }^{1}$

\begin{abstract}
Resumo: Este ensaio se faz a cavalgadas. A superfície que se percorre é composta por diversas texturas: os últimos três trabalhos cênicos concebidos pela dramaturga, performer e diretora Carolina Bianchi (Brasil) y Cara de Cavalo (coletivo de artistas que a acompanha): Mata-me de prazer $(2016)^{2}$, Quiero hacer el amor $(2017)^{3}$ e LOBO $(2018)^{4}$, chamados de Maratona das Paixões; e a possibilidade de produzir máquinas de guerra e nomadismos entre os veios vertiginosos dos autoritarismos em ascensão no capitalismo mundial integrado. Em bando cavalgamos juntos com Guattari, Deleuze, Preciado, Myers, Tsing e Tiqqun. Intenta-se experimentar nesta trajetória as aproximações possíveis com modos de subjetividade que combatam as estreitas formas assujeitadas e cafetinadas do presente e disparem com ponta de lança para novos modos de viver e experimentar o corpo em seus agenciamentos coletivos.
\end{abstract}

Palavras-chave: Artes cênicas; máquinas de guerra; pós-humanidade.

\begin{abstract}
This essay is done on horseback. The surface that is covered is composed of several textures: the last three scenic works conceived by the playwright, performer and director Carolina Bianchi (Brazil) and Cara de Cavalo (collective of artists that accompanies her): Matame de prazer (2016), Quiero hacer el amor (2017) and LOBO (2018), called Marathon of Passions; and the possibility of producing war machines and nomadism among the vertiginous veins of authoritarianism on the rise in integrated global capitalism. We rode together with Guattari, Deleuze, Preciado, Myers, Tsing and Tiqqun. The aim is to try, in this trajectory, the possible approximations with modes of subjectivity that combat the narrow subjugated and pimped forms of the present and shoot with a spearhead for new ways of living and experiencing the body in its collective assemblages.
\end{abstract}

Keywords: Performing arts; war machines; post-humanity.

Como explicar com palavras desse mundo que não há mais ninguém para lhe pesar a mão nos cascos? A humanidade. A humanidade. A humanidade é o nome de uma hiena pequena com dentes assassinos, a humanidade. Carolina Bianchi

\footnotetext{
${ }^{1}$ Rafael Limongelli é Doutorando em Educação (UNICAMP), Mestre em Educação (UNIFESP, 2017), bacharel em Ciências Sociais (PUC, 2013) e técnico em Artes Cênicas (INDAC, 2008) e publicou o livro de poemas Cretino (Ed. Patuá, 2013) e Duna (Ed. Patuá, 2018), colabora com ensaios, artigos e poemas nas revistas Alegrar (SP), Texturas (SC), Córrego (SP) e Barril (BA). Desenvolve pesquisas, críticas e práticas em artes integradas, transitando entre dança, teatro, performance, literatura e artes visuais. Atualmente integra o grupo de pesquisas Transversal (PPGE/UNICAMP) e é articulador cultural da Rizoma Livros e da FLIPEI - Festa Literária Pirata das Editoras Independentes. E-mail: rafaelimao@ gmail.com.

${ }^{2}$ Disponível em: https://arteview.com.br/saga-erotica-mata-me-de-prazer-de-carolina-bianchi-na-oswald-de-andrade/. Acesso em: 04 nov. 2019.

${ }^{3}$ Disponível em: https://www.revistabarril.com/gemer-a-gramatica-da-existencia. Acesso em: 04 nov. 2019.

${ }^{4}$ Disponível em: http://ycaradecavalo.blogspot.com/. Acesso em: 04 nov. 2019.
} 
Este ensaio se faz a cavalgadas.

A superfície que se percorre é composta por diversas texturas em dois platôs: o primeiro são os últimos três trabalhos cênicos concebidos pela dramaturga, performer e diretora Carolina Bianchi $^{5}$ (Brasil) y Cara de Cavalo (coletivo de artistas que a acompanha): Mata-me de prazer $(2016)^{6}$, Quiero hacer el amor $(2017)^{7}$ e LOBO $(2018)^{8}$, chamados de Maratona das Paixões; no segundo, trata-se da possibilidade de produzir máquinas de guerra e nomadismos entre os veios vertiginosos dos autoritarismos em ascensão no capitalismo mundial integrado.

Em bando cavalgamos juntos com todas as artistas da Cara de Cavalo, Guattari, Deleuze, Preciado, Myers, Tsing e Tiqqun. Intenta-se experimentar nesta trajetória as aproximações possíveis com modos de subjetividade que combatam as estreitas formas assujeitadas e cafetinadas do presente e disparem com ponta de lança para novos modos de viver e experimentar o corpo em seus agenciamentos coletivos.

Entre o começo da escrita e o envio deste ensaio, entre 2019 e 2020, Carolina Bianchi estreia uma nova peça: $O$ tremor magnífico (2020) no Teatro de Contêiner em São Paulo. Enquanto preparava este ensaio, relendo o texto de Mata-me de Prazer, deparei-me com a presença das 'mãos', de mãos enquanto signos, enquanto possibilidades de passagem para outros espaço-tempo, escreve Bianchi (2016):

Corpos de terra. Terra vermelha viva. A mãos já não reconhecem a luz. As mãos. Como poderíamos trepar o rochedo sem ela? Mãos humanas. Mãos animais. Mãos terríveis. Mãos molhadas. Mãos livres. Mãos. No novo continente se trepa até rachar o chão. No novo continente não se fala mais. Não se corre mais. No novo continente se devoram entre si. Multidão emocionada. A botar tudo abaixo. [meus grifos]

Aqui as mãos se rebelam contra a sua vulgar submissão ao corpo do trabalho, corpo suturado na função de servir à extração da mais valia pelo trabalho e à docilidade pelos aparelhos de Estado. São mãos para pôr tudo abaixo. São mãos insubmissas, mãos de trepar com rochedos até que se tornem uma outra coisa, nem rochedo, nem pessoa, outra formação, nem pessoa e nem coisa. Mãos engajadas em transfigurar o corpo. Em quiero hacer el amor, em $L O B O$ e com força em $O$ Tremor Magnífico as mãos reaparecem, atualizam-se e se dispersam.

\footnotetext{
${ }^{5}$ Entrevista com Carol Bianchi para o canal Arte 1 (2020): https://www.youtube.com/watch?v=56_UY48rGgE.

${ }^{6}$ Disponível em: https://arteview.com.br/saga-erotica-mata-me-de-prazer-de-carolina-bianchi-na-oswald-deandrade/. Acesso em: 04 nov. 2019.

${ }^{7}$ Disponível em: https://www.revistabarril.com/gemer-a-gramatica-da-existencia. Acesso em: 04 nov. 2019.

${ }^{8}$ Disponível em: http://ycaradecavalo.blogspot.com/. Acesso em: 04 nov. 2019.
} 


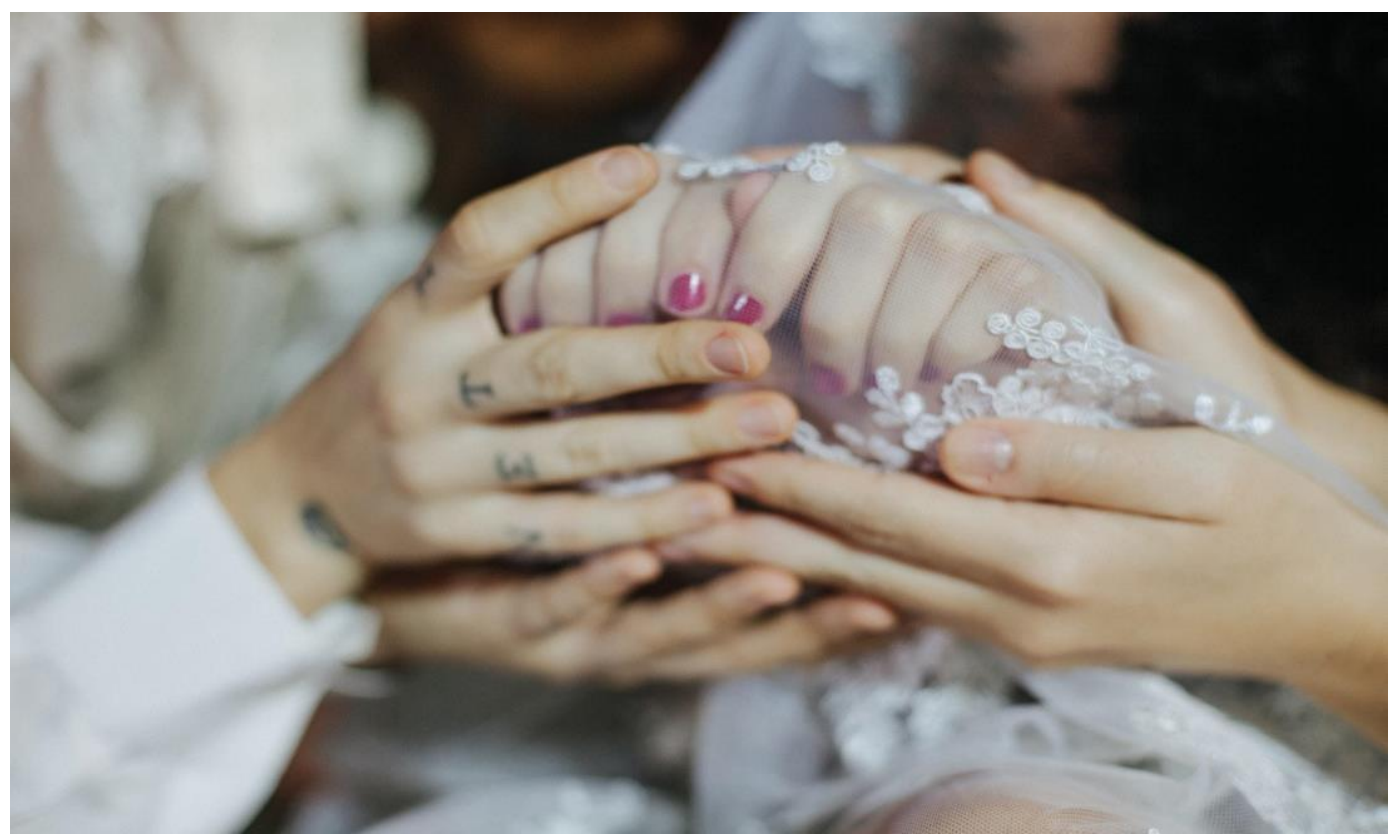

Foto de Mayra Azzi em apresentação de $O$ Tremor Magnífico no Teatro de Contêiner.

As mãos, como um signo e uma estrela dentro de dessa cartografia, as mãos, neste texto são um indicador de um procedimento de pensamento e criação que atravessa o trabalho de Carolina Bianchi: as coisas morrem e não morrem, não desaparecem, persistem, retornam, atualizam-se, e no mesmo lance, somem. A presença das mãos não me apresenta uma suposta linearidade da pesquisa de Bianchi. Pelo contrário, apresentam uma coragem obstinada da criadora em levantar mundos e com horror e prazer os abandonar. Seguir adiante, praticar nomadismos, não civilizar os mundos, não sedentarizar os corpos dos mundos. Talvez, acumular algumas armas de insubordinação, como esse outro uso das mãos, para construir máquinas de guerra, como Deleuze e Guattari (2012) comentam

Mas o regime da máquina de guerra é antes a dos afectos, que só remetem ao móvel em si mesmos, a velocidades e a composições de velocidade entre elementos. $\mathrm{O}$ afecto é a descarga rápida da emoção, o revide, ao passo que o sentimento é uma emoção sempre deslocada, retardada, resistente. Os afectos são projéteis, tanto quanto as armas (2012, p. 84).

Máquinas de guerra anti-Estatais que se manifestam em nossos corpos. Atiçar guerra contra o corpo sedentarizado pelas cidades, cerealizado pelo regime de plantation, heteronormativizado pelo patriarcado, domesticado pelas palavras, etc. O corpo produzido por Bianchi é vivo e atravessa para fora da hegemonia do humano, um atentado por um corpo agenciado entre humanos e não humanos, animais empalhados, fantasmas, memórias, metal, terra, flores.

Esse ensaio é uma corrida com os olhos fechados por um espaço desconhecido. Um percurso com o trabalho de Carolina Bianchi para percorrer caminhos de desaparecimento. Caminhar lado a lado segurando uma faca pelo fio. Para tanto, cavalgaremos por sete platôs que estão organizados na seguinte composição:

\section{- territórios y nomadismos}

- levitação y deriva

- sexo y superfícies

- feminismos y pós humanidade 


\section{- morrer y suor}

- zona indistinta y sem metrificação

\section{territórios y nomadismos}

A guerra é política continuada por outros meios, como afirmou Foucault (2010, p. 10) no curso Em defesa da sociedade. Neste período, o filósofo se dedicava a investigar as operações de governo e governamentalidade. Se a política era a relação entre as nações e no limite da defesa do território se dá a guerra - como sentencia Clausewitz - a afirmação de Foucault faz inverter o quadro de análise para uma atividade de governo dos territórios sobre si mesmo - é preciso governar os fluxos populacionais para extrair obediência e produção. É neste curso de 1975-76 que o conceito de racismo de Estado se desenvolve como uma ação biopolítica que incide sobre a sociedade para produzir sujeitos e domesticar os corpos, fazendo viver alguns, deixando morrer outros tantos. Uma guerra contra um inimigo que está dentro das fronteiras do Estado em nome da defesa da sociedade.

Deleuze e Guattari (2012), inflamam essa análise ao escrever sobre as relações possíveis entre as máquinas de guerra e aparelhos de captura do Estado.

A máquina de guerra se encarregou do fim, da ordem mundial, e os Estados não passam de objetos ou meios apropriados para essa nova máquina. É aí que a fórmula de Clausewitz se revira efetivamente, pois, para poder dizer que a política é a continuação da guerra por outros meios, não basta inverter as palavras como se se pudesse pronunciá-las num sentido ou no outro, é preciso seguir o movimento real ao cabo do qual os Estado, tendo-se apropriado da máquina de guerra, e fazendo-o para seus fins, devolvem uma máquina de guerra que se encarrega do fim, apropria-se dos Estados e assume cada vez mais funções políticas (2012, p. 117).

As máquinas de guerra são formações anti-Estatais. Não são elas que fundam a origem dos Estados e seus territórios como doutrinou toda tradição de pensamento da Filosofia Política Clássica. Ainda que máquinas de guerra possam ser capturadas por aparatos de Estado. As máquinas de guerra são práticas que acontecem em um espaço liso, a atividade essencial é o trabalho turbilhonar e livre, é povoada de armas com seus gestos projetivos, ocupam não lugares em variação contínua, as armas, aqui, são afectos. Enquanto o aparato de Estado é uma captura que produz um espaço estriado, demarcado, metrificado, inaugura um território, uma escritura e uma contabilidade próprias e régias, a atividade do aparato de Estado é o trabalho e o sobre-trabalho (mais-valia), é povoado por ferramentas que atuam em deslocamentos lineares e com centro de gravidade estabelecido, aqui, as ferramentas são os sentimentos, em oposição aos afectos.

Ponto a ponto, a máquina de guerra e o aparato de Estado se opõem. Essa oposição pode ser entendida como uma agonística. Agon é o atrito dos corpos dos guerreiros enquanto lutam, é rangido dos corpos se esfregando em batalha, é o rangido das máquinas em choque. Ambos estão conectados sob uma mesma matéria movimento, uma matéria humana, animal e nãohumana, inanimada, essa matéria-movimento é um phylum (conceito emprestado da biologia), comenta Deleuze (2017) em um curso de 1979,

Um verdadeiro phylum que atravessaria tanto as máquinas de guerra como os aparatos de Estado. Um phylum inanimado, animal e humano, atravessaria 
tudo isto. E esse phylum, por natureza, já não seria nômade como as máquinas de guerra, nem sedentário como os aparatos de Estado, seria fundamentalmente (...) itinerante (2017, p. 28 , tradução do autor).

Talvez seja nesse rangido entre as lutas por liberação das máquinas de guerra em relações de resistência e captura por aparatos de Estado que esteja a constituição da política. Política como invenção de um comum, invenção dos espaços possíveis para criação de novos mundos, disponíveis para destruição de mundos que já existem e a disputa em torno do gerenciamento do presente, em suas atualizações. Um rangido da luta entre captura e liberdade de máquinas de guerra delirantes. Um espaço esburacado, que não é liso, que não é estriado, que atravessa os dois campos. O trabalho de Bianchi está nesse gesto itinerante entre um corpo esburacado, que entra por debaixo da pele um do outro, entre horror e paixão, civilização e ocultismo etc.

\section{levitação y deriva}

Uma paisagem. Nela o fundo e o primeiro plano se confundem. Anti-fundo e Anti-frente. A voz de Carolina Bianchi convoca em todos os cantos do mundo o tesão. Um tesão-prática, um tesãomodo-de-vida, um tesão-afirmação-de-si-no-mundo. Sentada, faz uma palestra sobre um pedaço de terra que se desprega do continente e entra em deriva. Ela fala enquanto Lucas Vasconcelos (2016) e Tom Monteiro (2018) a acompanham manipulando seus fios eletro-acústicos produzindo uma composição ambiental e cosmológica: uma invenção de uma nova origem para um novo povoamento e uma nova experiência do vivo. "Imaginem um país dentro de um continente. Agora imaginem um país que se torna um continente. Um grande pedaço de terra flutuante. Flutuando devagar no meio do oceano. Um pedaço de terra que se move muito lentamente" (BIANCHI, 2016).

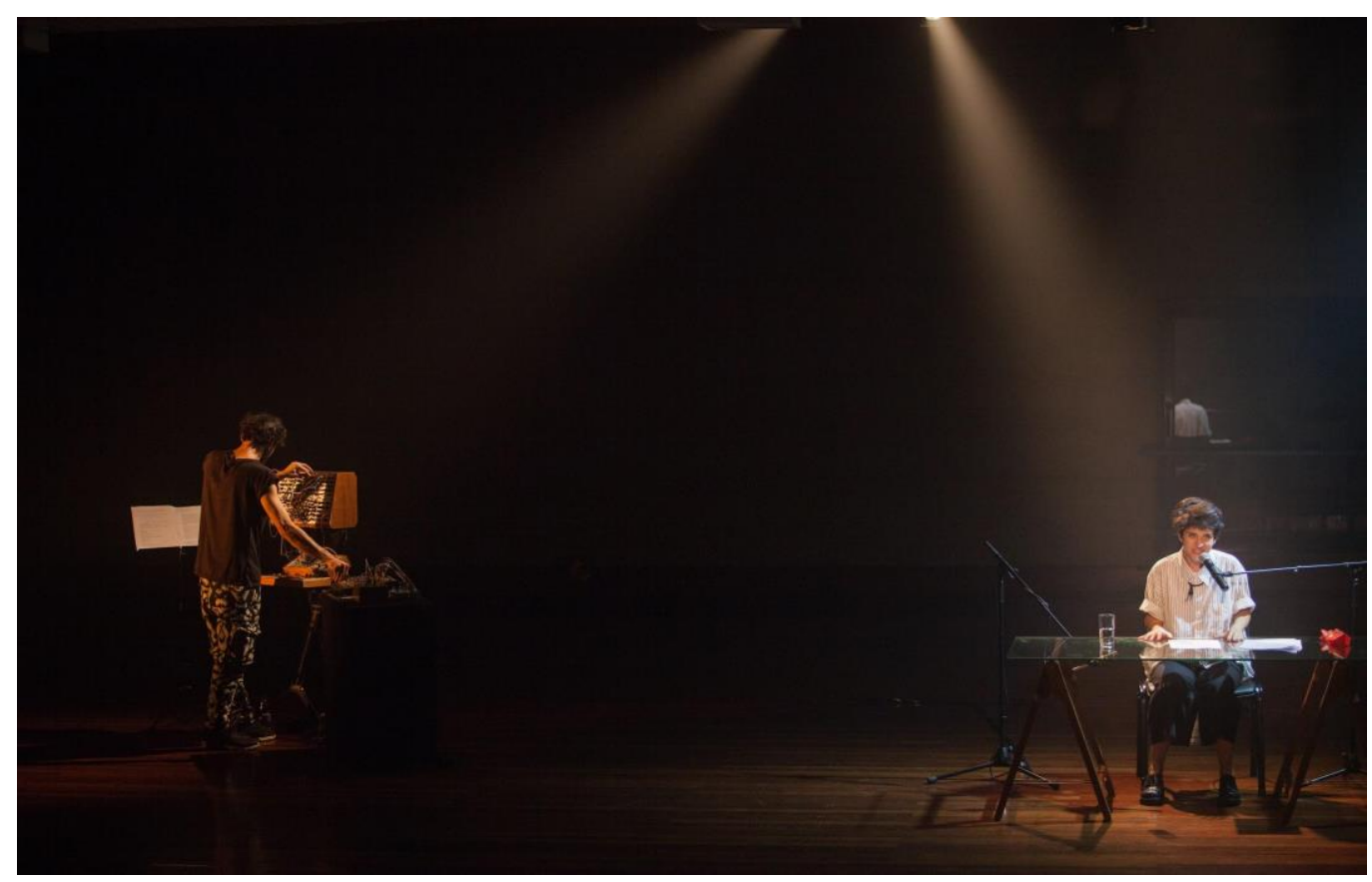

Foto de Mayra Azzi em apresentação no SESC Vila Mariana.

Bianchi constrói um país que se desprende do resto do mundo e deriva flutuando. Neste território em deriva, os povoamentos vão se transformando. O primeiro ministro faz um comunicado ordenando que tudo se abra - bocas, zoológicos, cadeiras, túneis, portas, - tudo se 
abra! Ao dizer isto, masturba-se junto aos macacos e morre abraçado a um crocodilo. Cientistas desse novo continente se esfregam em pedras pensando em tartarugas de Galápagos e dizem:

Vale morrer a perseguir o êxtase do orgasmo da relação do corpo humano com
a pedra. Vale morrer esfolado a perseguir o auge da relação erótica entre
matérias. diferentes, como é a matéria do corpo humano e a superfície de uma
rocha. Vale se desequilibrar de paixão por uma rocha. Vale sucumbir ao desejo
da pedra, senhores. (BIANCHI, 2016).

Conta-nos, Bianchi, que o alfabeto está progressivamente sendo abandonado e novos sons têm surgido "tudo é canção ao contrário" (BIANCHI, 2016). As pessoas dedicam de seis à oito horas por dia para os prazeres consigo e com os outros, o sexo, as carícias, os carinhos, as brincadeiras, o gozo, o orgasmo são as funções principais que o trabalho do novo continente prescinde, cuidar de si e cuidar dos outros oito horas por dia, falar sobre si, sonhos, ouvir sobre histórias. Os telefones celulares são trocados pela telepatia.

A represália é mundial, as organizações internacionais, países, igrejas, todos se mobilizam para proibir a existência do novo continente. Enviam missões de colonização e guerra. Alguns tentar a nado chegar ao novo continente para pedir asilo. "Mas o novo continente parece sempre escapar ao tempo da velocidade do resto do mundo" (BIANCHI, 2016).

Incapturável, este novo continente é itinerância. Fluxo de variação de tudo e continuamente. Movimento profundo de desterritorialização. Ao contrário dos impérios que "caem e se levantam e caem e se levantam de novo" (Idem.), o novo continente é o próprio movimento de cair e levantar, o movimento da correnteza que traga tudo e todos pela história é a própria força de invenção-destruição. Assemelha-se ao phylum de matéria-movimento de Guattari e Deleuze, agenciando animais, humanos, não-humanos, vegetais e inanimados.

A pesquisadora anticolonialista Natasha Myers, ao escrever How to grow livable worlds: Ten not-so-easy steps [Como criar mundos habitáveis: dez passos não tão fáceis], faz um atentado contra a tentativa brutal de dominação do pensamento Antropocêntrico, percepção hegemônica nas sociedades capitalísticas que vivemos, comenta Myers (2018)

Repita este mantra: Nós não estamos sozinhos. Nós não estamos sozinhos. Nós não estamos sozinhos. O pensamento antropocêntrico é tão obcecado pela independência do homem, pela ação unilateral e pela autonomia, que esquece que existem outras forças e poderes entre nós, incluindo aqueles com habilidades significativamente melhores no domínio da criação de mundos e das mudanças em escala planetária (MYERS, 2018, p. 57, tradução do autor)

Não estamos sozinhos! Estar junto.

Vivemos entre outras experiências do vivo (animal, vegetal, incorporal, inanimado, virtual etc). Vivemos por perto de comunidades inteiras de florestas em interação multiespécies, com diferentes eras geológicas, com informações ultrarrápidas etc. Não se trata de uma ecologia submetida e codificada aos padrões do capital e a seu serviço. Trata-se aqui de um atentado de uma máquina de guerra contra um aparato de Estado. Um atentado contra o sistema colonial, patriarcal, estatal, capitalístico em escala regional e planetária. Investindo em nossa capacidade de criar outros mundos agora, aniquilar o que veio antes e especialmente reinventar nossos corpos, nosso imaginário.

Talvez um primeiro passo para a descolonização exija que detonemos nossa imaginação colonial. Para fazer isso, precisaríamos reverter tudo o que 
acreditamos ser senso comum. É hora de esquecer tudo o que você pensou que sabia sobre o mundo dos vivos, especialmente o que você acredita ser perceptível, imaginável, razoável, legível e significativo (MYERS, 2018, p. 62, tradução do autor).

\section{sexo y superfícies}

Os corpos se espraiam por toda América Latina, atrás da orelha de um burro, pelas pernas que cruzam constantemente os metrôs, pelos desertos do continente africano, pela rua de casa, pela biboca do capão redondo. Pululavam multiplicidades! Direções delirantes no espaço. Localização orientada pelo desejo ingovernável, pelo erótico de cada humano e não-humano que há no espaço.

Sexo.

Fazer sexo com o espaço e seus povoamentos em variação contínua. Desorganizar os laços que atam os sujeitos, os verbos e os objetos. A performance agencia corpos humanos e não humanos na composição de máquinas (técnicas e sociais). Máquina de guerra meio torpe, surubão pós-pornográfico.

$\mathrm{Na}$ orgia disparada por Bianchi, performers despossuídas de suas sujeições reconectam a possessão de si mesmas em ações disruptivas, como "acariciar com prazer o teclado do telefone público" e "penetrar com o punho o porta-guarda-chuvas" e "roçar com carinho as escápulas no caule de uma planta" e "friccionar com fúria o totem-informativo contra o chão" e "amassar o rosto com tesão contra a parede de vidro" e "abrir com ternura e sensualidade as pernas da porta de vidro" etc.

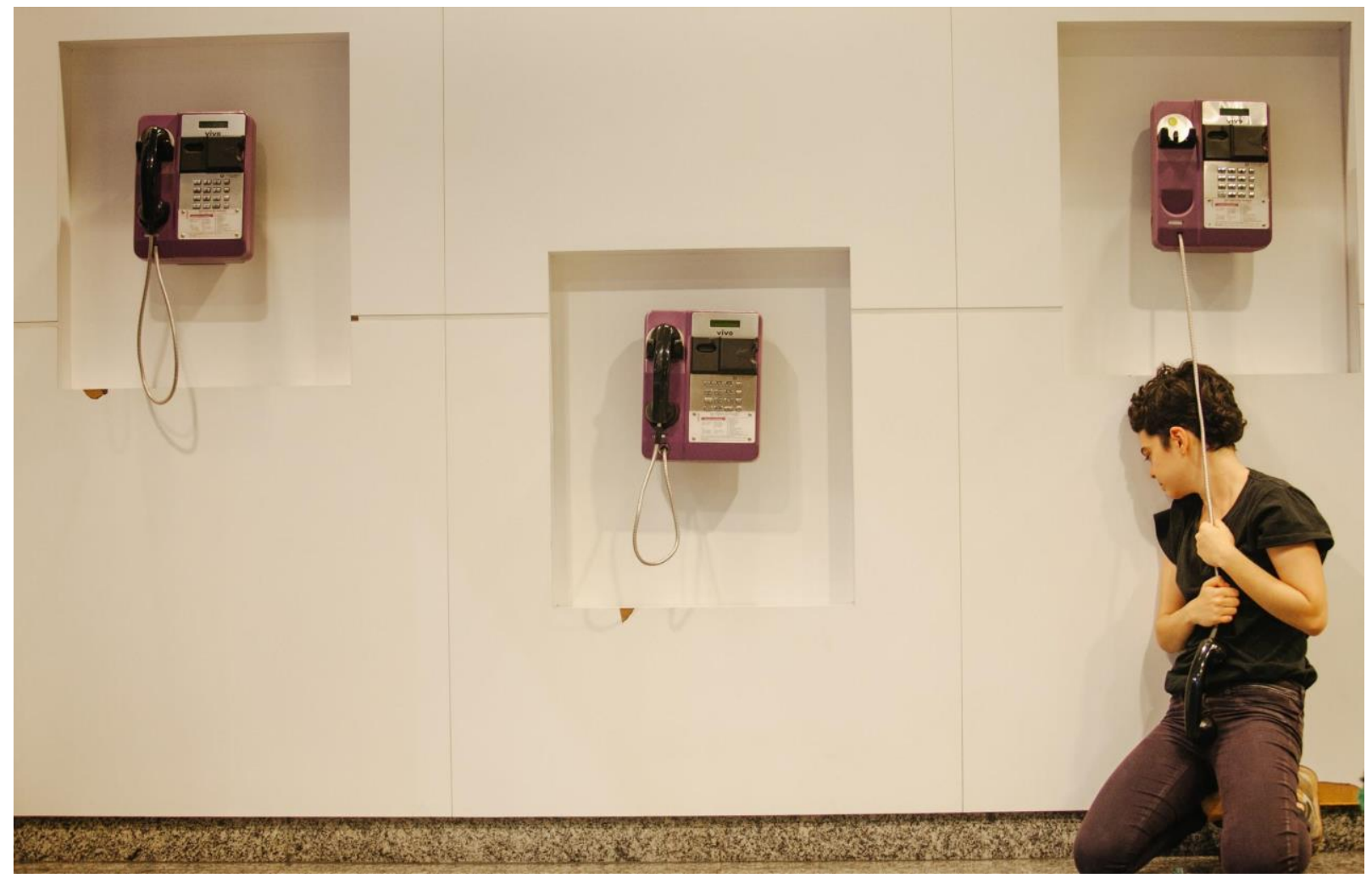

Foto de Mayra Azzi em apresentação de quiero hacer el amor no SESC Santana.

As performers atravessavam o território esquadrinhado-estriado dos espaços culturais de sociabilidade movendo forças de alisamento. O que as conduz não é acessível às codificações, uma cosmologia embebida no embaralhado da linguagem e da gramática que a máquina heteronormativa escreve nos corpos. Explosão dos significados reconhecíveis. Elas se atiram 
de um desejo a outro, de uma conexão a outra sem plano de voo ou roteiro prévio. São forças de expansão das possibilidades de percepção daquele espaço, expansão das possibilidades de percepção do corpo entre o que é permitido-aconselhável e o que é inimaginável, impossível, invisível, impensável e indizível. Uma capacidade de afetar, perceber, ser afetado e ser percebido. Elas não estão defendendo uma pauta, uma bandeira, uma aula, um conselho sobre "como devemos viver" e sobre "o que você deve fazer".

Elas faíscam.

Incendeiam quem se permitir queimar.

\section{feminismos y pós humanidade}

Em seu Manifesto Contrassexual (2017), Preciado inflama um debate anti-patriarcal, antiprodutivo e anti-heteronormativo. Pouco importa para contrassexualidade a origem dos gêneros, ou suas essências, não há verdades ocultas para se revelar e nem continuidade histórica que nos leve a uma origem do homem e da mulher, como Adão e Eva. Não há natureza de papéis, funções e práticas para cada gênero e sexualidade. Uma contrassexualidade que instaura práticas de contestação de hegemonias e práticas autoritárias. Que atenta por uma chance de inventar outras sexualidades possíveis para além do corpo-homem e corpo-mulher - atacando estruturas de poder, comenta Preciado (2017): “Os papéis e as práticas sexuais, que naturalmente se atribuem aos gêneros masculino e feminino, são um conjunto arbitrário de regulações inscritas nos corpos que asseguram a exploração de um sexo sobre o outro. (p. 26).

O transfeminismo é uma política da terra (PRECIADO, 2018, p. 13). Não convoca apenas as mulheres para perfilar sua batalha, e sim, e convoca "usuários críticos das tecnologias de produção da subjetividade" (2018, p. 11).

Nós somos o parlamento pós-pôrno que está por vir. Eles dizem 'representar'. Nós dizemos 'multitude'. Eles dizem 'dívida'. Nós dizemos 'cooperação sexual e interdependência somática'. Eles dizem 'capital humano'. Nós dizemos 'aliança multiespécies'. Eles dizem 'crise'. Nós dizemos 'revolução (PRECIADO, 2018, p. 14).

A minha bandeira, meus senhores, é uma coluna arrancada com a mão, diz Bianchi no início da peça LOBO, no primeiro ato. Um hiena sanguinária. A morte do homem. O mundo dos homens precisa morrer. No entanto, não é sobre a vitória do mundo das mulheres, em oposição ao corpo-homem. Não há conciliação! É treta, atrás de treta. A experiência do vivo não pode, não deve, ser apaziguada na aniquilação de uma identidade em nome de outra identidade. Nos binarismos insistimos na política identitária, assujeitada. A guerra dos sexos está dada, com suas assimetrias bem claras e definidas: tudo que não seja hetero-cis-dominantesujeito-com-nome-civilizado-ocidental-branco-limpo-asséptico deve ser sujeitado e explorado, e caso se rebele, deve ser eliminado. Nessa chave, o mundo dos Homens precisa morrer! Nada sobre masculinidades menos tóxicas, masculinidade desconstruída etc. Em vez de curar o incurável, deixar morrer (e matar!). E que essa morte faça emergir um imensidão sem fim de experiências do corpo, insubordináveis a qualquer aparato de captura dos nomes patogênicos.

Preciso me tornar anônima. Para estar / presente./ Quanto mais sou anônima, mais estou presente./ Preciso de zonas de indistinção / para ter acesso ao Comum. / Para não mais me reconhecer em meu nome. Para / em meu nome só ouvir a voz que o / chama./ Para fazer consistir o como dos seres, não o / que eles são, mas como são o que são./ Sua forma-de-vida. / Preciso de zonas 
de opacidade onde os atributos,/ mesmo criminosos, mesmo geniosos,/ não mais separem os corpos. (TIQQUN, 2019, p. 9)

Uma identidade de gênero no anonimato de si mesmo! Nunca cessar de percorrer as sexualidades, sem nunca se fixar. Mobilidade e experimentação incessante de si mesmo. A possibilidade de produzir a própria experiência de ser-vivente escapa às amarras da identidade e do nome quando mobilizada por um processo de subjetivação de si sobre si mesmo. Talvez, a experiência do anonimato, do sem-nome, sem-identidade, sem-gênero, sem-sexualidade pode fazer embaralhar as estruturas de poder que desejam separar, distinguir e qualificar e se abrir para nomes-todos, identidades-todas, gênero-todos.

\section{morrer y suor}

Ainda no texto de Mata-me de prazer, encontramos a seguinte frase: "O moderno é o desespero do macaco que nunca quis ser homem." (BIANCHI, 2016). Essa mesma frase foi enviada como disparador para artistas se inscreverem em uma residência de pesquisa da peça LOBO com Carolina Bianchi em novembro de 2017. Na inscrição era preciso enviar uma imagem disparada por essa frase. A peça estreia em 2018 e se apresenta até 2020, entre São Paulo, Rio de Janeiro, Porto Alegre e entre festivais nacionais e internacionais, teatros independentes e teatro estatais, e estava com viagem programada para Nova Iorque (EUA) em abril de 2020, sendo cancelada pelas restrições impostas pela pandemia do covid-19.

Homens correm intensamente, sem direção, desordenados, por muito tempo, levados a exaustão, nus, com garrafas de vidro nas mãos. Uma mulher mata muitos homens enquanto os homens tentam falar um poema. Homens e mulheres tentam forjar um set de cinema. Um estômago é arrancado com as mãos. Uma lagosta fala que homens e mulheres andarão de mãos dadas segurando uma faca pelo fio. Homens e mulheres trocam saliva. Uma lagosta vira corpo humano. Uma tinta fluorescente vira corpo humano. O corpo humano desaparece. Não há mais sexos. Nada se resolveu. A equação permanece insolúvel.

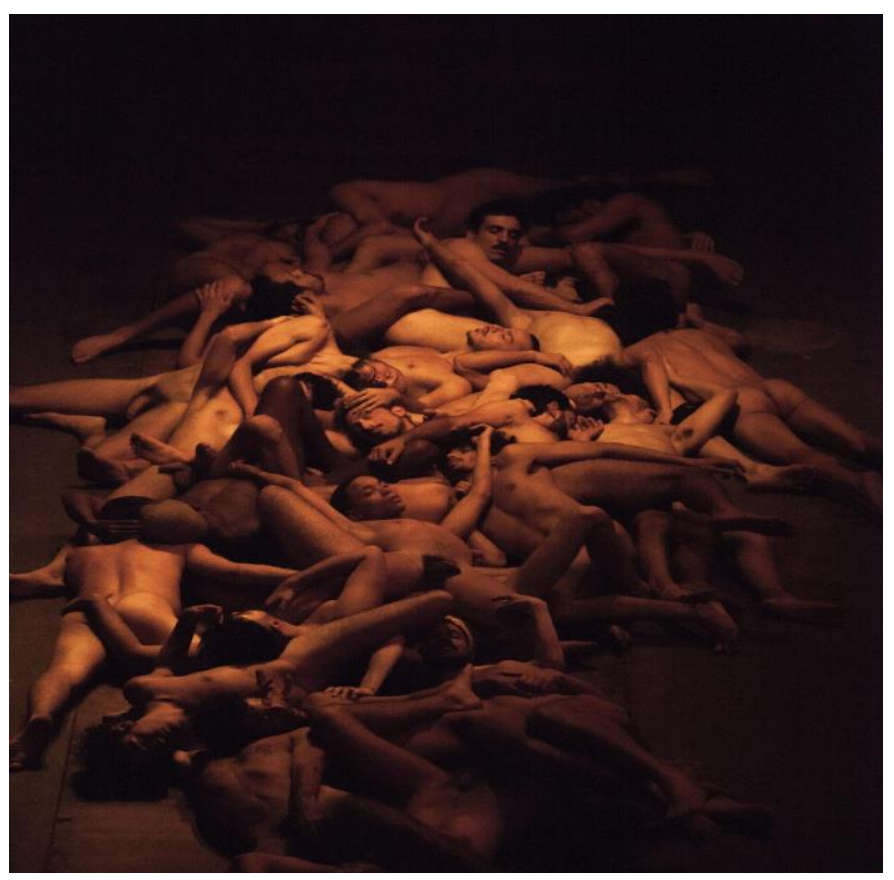

Foto de Mayra Azzi em apresentação no Teatro Oficina Uzyna Uzona. 
Em LOBO, morte, sexo, guerra, terror, cinema, ficção, tudo se mistura, tudo se torna superfície. Há apenas zonas de indistinção. Grandes manchas e borrões por toda a parte. As imagens se formam e logo são abandonadas. Nunca nada é levado à lugar algum. Um sonho. Um nightmare, uma égua cavalgando a noite sem ver um palmo a sua frente, bufando com paixão. Uma ameaça à segurança e à estabilidade. Um atentado terrorista contra as artimanhas das definições de gênero que a máquina social heteronormativa-patriarcal-capitalística insiste em imprimir sobre os corpos (humano e não humanos).

A palavra civilização, por exemplo, me causa imenso transtorno na face porque a civilização abre nossas mandíbulas até rasgar nossa cara. mas isso era antes. antes de encontrarmos um rastro de saliva tóxica nos apartamentos e móveis e carpetes e na louça da pia, ou nas calcinhas que eventualmente usamos ao contrário, antes de perceber o rastro de sangue para que mais lobos apareçam para que lobos e lobos e lobos e lobos vão arranhar as suas portas e todos ficarão em silêncio transpirando numa montanha de gente e de animais domésticos para não porque não queremos que lobos e lobos e lobos apareçam mas lobos e lobos e lobos vão invadir as casas e cagar e mijar em tudo, e vão beber as nossas bebidas, e vão abrir os armários e usar as suas camisetas com frases curtas interessantes, e lobos e lobos vão usar as mandíbulas para tentar dizer uma única palavra mas vai ser impossível encontrar a palavra porque só vão restar as línguas tentando devorar tudo que encontram pela frente e lobos e lobos e lobos vão andar sobre os parapeitos de todas as florestas- tropicais ou congeladas- e lobos e os lobos vão sobrar até que o musgo cubra todos os nossos nomes e tudo se acaba e fim (BIANCHI, 2018-2020).

Podemos tomar de empréstimo as análises de Guattari e Deleuze (2011) no platô 1914Um só ou vários lobos? em que elaboram uma ode anti-freudiana, apontando para uma perspectiva do inconsciente como uma espécie de multidão povoada por variações e intensidades. Nesta análise temos alguns arranjos interessantes para pensar os lobos que Bianchi diz em seu texto. O que não significa afirmar que Bianchi fala sobre esses lobos de Guattari e Deleuze, pelo contrário, suas conversações e aproximações se dão no pensamento por caminhos muito diferentes. No entanto, está análise permite aproximar os estranhos e disparatados.

Ao contrário da massa, da posição da massa que fica "em silêncio transpirando numa montanha de gente e de animais domésticos" (BIANCHI, 2018), os lobos são formações de corpos-sem-órgãos, são "intensidades, velocidades, temperaturas, distâncias variáveis indecomponíveis. É um formigamento, uma inflamação" (DELEUZE; GUATTARI, 2011, p. 59). Lobos e lobos e lobos são forças de desorganização, de variação do fluxo que organiza o corpo, de atenção e conspiração com outras materialidades, uma invenção de novos usos para os agenciamentos que codificam o corpo. Zonas de tesão por toda superfície do corpo e do palco e da plateia e do ar e das memórias e por onde houver espaço para fazer deslizar o desejo.

Campo de ânus assim como matilha de lobos. E não é pelo ânus que o menino está ligado aos lobos, à periferia? Descida do maxilar ao ânus. Unir-se aos lobos pelo maxilar e pelo ânus. Um maxilar que não é mandíbula, não é tão simples, mas maxilar e lobo formam uma multiplicidade que se modifica no olho e lobo, ânus e lobo, segundo outras distâncias, conforme outras velocidades, com outras multiplicidades, nos limites de limiares. Linhas de fuga ou de desterritorialização, devir-lobo, devir-inumano, intensidades desterritorializadas - isto é a multiplicidade. Devir-lobo, devir buraco, é desterritorializar-se segundo linhas distintas emaranhadas (DELEUZE; GUATTARI, 2011, p 59). 


\section{zona indistinta y sem metrificação}

Durante seus últimos trabalhos Bianchi têm se dedicado a promover encontrar disruptivos com o público, não procura nenhuma atividade conciliatória de nenhum conflito em relação à linguagem, à paixão, ao sexo, ao gênero. Seu ato criativo é uma guerra, uma máquina de guerra nômade, associada muitas vezes com outras artistas, que itineram pelos espaços ainda respiráveis da produção teatral brasileira. Vem erguendo em peças de teatro como acontecimentos intempestivos que inauguram máquinas de guerra e nomadismos. Atentados contra as formações dos aparatos de Estado e suas capturas.

Bianchi conjura zonas de indistinção em que os nomes, os códigos, os estado, as leis, os valores, as normas, os dogmas, todos eles, caem por terra e conjuram uma afirmação de vida nova, vida liberada, vida outra, vida a cavalgadas pelo breu.

\section{Referências}

BIANCHI, Carolina. Mata-me de Prazer [Texto de Teatro]. Apresentado em Oswald de Andrade (2016), Sesc Vila Mariana (2018), Flipei (2019).

BIANCHI, Carolina. $L O B O$ [texto de teatro]. Apresentado em Teatro de Conteiner, Festival Cena Brasil Internacional, Festival Internacional de Teatro de São Paulo, Sesc, entre outros (2018-2020).

DELEUZE, Gilles. Derrames II: aparatos de estado y axiomática capitalista. Buenos Aires: Cactus, 2017.

DELEUZE, Gilles; GUATTARI, Felix. Mil platôs: capitalismo e esquizofrenia 2, vol. 5. São Paulo: Editora 34, 2012.

DELEUZE, Gilles; GUATTARI, Felix. Mil platôs: capitalismo e esquizofrenia 2, vol. 1. São Paulo: Editora 34, 2011.

FOUCAULT, Michel. Em defesa da sociedade, curso de 1975-76. São Paulo: Martins Fontes, 2010.

MYERS, Natasha. How to grow livable worlds: ten not-so-easy steps. In: SMITH, K. O. Smith (Ed). The world to come. Gainsville, Florida: Harn Museum of Art, 2018. p. 53-63.

PRECIADO, Paul B. Manifesto contrassexual. São Paulo: N-1 Edições, 2017.

PRECIADO, Paul B. Transfeminismo. São Paulo: N-1 Edições, 2018.

TIQQUN. Como fazer? Como Desertar? São Paulo: N-1 Edições, 2019. 